\author{
Guy Stéphane Padzys*, Jean Marc \\ Martrette and Marie Trabalon \\ Département de Biologie, P 943 Franceville/Gabon, \\ Université des Sciences et Techniques de Masuku, \\ France \\ Dates: Received: 28 August, 2015; Accepted: 14 \\ October, 2015; Published: 19 October, 2015 \\ *Corresponding author: Guy Stéphane Padzys \\ Département de Biologie, P 943 Franceville/Gabon, \\ Université des Sciences et Techniques de Masuku, \\ France, E-mail:padzys@gmail.com \\ www.peertechz.com \\ ISSN: 2455-4634
}

Keywords: Nasal obstruction; Olfactory bulb; Histology; Hormones

\section{Research Article \\ Impact of Early Nasal Obstruction in Histological Development of and Physiological State}

\section{Introduction}

Nasal obstruction is considered a risk factor in sleep-disordered breathing [1-3], which has a very negative impact on quality of life in children and adults with increased daytime sleepiness [4]. This symptom resembles that of obstructive sleep apnea (OSA) caused by episodes of upper airway obstruction leading to episodic hypercapnic hypoxia which alters upper airway muscle structure and fiber type expression [5]. The most common clinical manifestations of OSA are nocturnal snoring, respiratory pauses, restless sleep and mouth breathing [6]. This disturbed breathing is known to produce lethargy, cognitive impairment and sleep impairment, especially in children $[7,8]$

Chronic nasal obstruction is a non-specific condition observed in many pathological conditions, e.g. rhinitis. Nevertheless, because this disorder is not life threatening (at least in adults) its importance could be underestimated. Impaired nasal breathing results in obligatory oral breathing, which can be divided into two components: chronic absence of active nasal respiration that results in an olfactory deprivation [9], and chronic mouth opening [10] Furthermore, in contrast to oral breathing, nasal breathing allows the optimal conditioning of inhaled air, clearing, moistening and warming the air before gas exchange in the lung $[11,12]$.

Obligatory mouth breathing has been observed in human babies and has been associated with a number of conditions that could have both short and long term effects on the physiology and thus behavior of these infants later on in adolescence. Decreases in oxygen saturation and respiratory frequency, with an increase in arousal were observed with nasal occlusion in preterm infants [13]. If untreated oral breathing in children can induce long narrow faces, narrow mouths, high palatal vaults, dental malocclusion, gummy smiles and other effects like skeletal facial profiles. These children do not sleep well at night and this lack of sleep can adversely affect growth and academic performance $[8,14]$.

In other words, it is possible that nasal obstruction causes a loss of the sense of smell and this hyposmia could disrupt the orientation of young rats to the mother, with consequent deprivation of food and feeding. It has been shown in rats that deprivation of food for 3 days causes a diminution in thyroid hormones [15] associated an increase in stress hormones [16].

No study has shown the long-term impacts of early nasal obstruction, associated with oral breathing, on development of olfactory bulb in the rat. The aim of the present investigation was to evaluate the effect of early short-term ( $3 \mathrm{~d}$ ) nasal obstruction, associated with oral breathing, on olfactory bulb long term $(90 \mathrm{~d}$, adult) impact. Our hypothesis was that nasal obstruction would have a significant effect on olfactory bulb development during the very short period of forced oral breathing. The effect of early nasal obstruction on olfactory bulbs and on hormonal status was also studied. In particular, the stress response and plasma levels of thyroid hormones T3 and thyroxine (T4) were evaluated to determine if these hormones could be implicated in olfactory bulb histology development during early nasal obstruction. 


\section{Methods}

\section{Animals}

Forty-two male Wistar rats (IFFA-CREDO, France) were used for this experiment. The animals were born in the laboratory from twenty litters, culled to 7 pups per litter to ensure normal body growth. The animals were housed in standard cages under controlled temperature conditions $\left(22 \pm 1^{\circ} \mathrm{C}\right)$. Food and water were available ad libitum throughout the experiment. From birth, the rats were kept on a reversed 12:12 light-dark cycle (dark period 08:00-20:00).

\section{Nasal obstruction procedure}

All experiments conformed to the Guide for the Care and Use of Laboratory Animals published by the National Institutes of Health (no. 85-23, revised 1996), the recommendations of the European Community Council for the Ethical Treatment of Animals (no. $86 / 609 /$ EEC) and the regulations of the University of Nancy 1 . All efforts were made to minimise animal suffering. At the age of 8 days (D8), the litters were first anesthetised. Animals were weighed and they were then divided randomly into one control group and one experimental group (oral breathing). Bilateral nasal obstruction, resulting in forced oral breathing, was performed in experimental animals (7 per age) as described previously by Meisami [10], and Waguespack et al. [17]. The selected method consisted in the cauterisation of the external nostrils, which is the most common and simple procedure allowing spontaneous reopening of nostrils after 4 days. The tissue surrounding the external nostrils was burned by placing a surgical cauterising instrument $(1 \mathrm{~mm}$ in diameter) on the nostrils, consequently occluding the orifice of the nostrils without mechanical or chemical damage to the olfactory mucosa. This procedure induced complete nasal obstruction between D8 and day 11 (D11) with $100 \%$ of the nostrils spontaneously reopened by day 15 (D15).

The sampling experiments were conducted during complete nasal obstruction day 9 (D9) and day 11 (D11) and at 90 days after post-reopening of the nostrils, i.e. at the beginning of adulthood (Figure 1). The animals started breathing through their mouths immediately after nasal occlusion, as has been reported in infant ${ }^{8}$. Nostril cauterisation earlier in life resulted in rapid death of the pups. In the control group (7 per age), the nostrils were not sealed but the cauterising instrument was placed about $1-2 \mathrm{~mm}$ above each nostril to burn the skin. After cauterisation, the nostrils were washed with chlortetracycline (Aureomycine Evans 3\%) to prevent infection. The pups were warmed $\left(37^{\circ} \mathrm{C}\right)$ for $30 \mathrm{mn}$ and returned to their mothers. Exploratory and feeding behaviours of the pups after weaning were the same for both cauterised and control group rat pups suggestive of no serious long term central effects of the treatment, especially in the forced oral breathing group [18].

\section{Sample collection}

Seven rats per group (control and oral breathing) and per sex (D90) were removed, immediately humanely killed, weighed and an intracardiac blood sample (500-1000 ml) was taken between $11 \mathrm{~h}$ and noon for hormonal measurements. Blood was collected over 1-2 min into sterile heparinised syringes fitted with a $26-\mathrm{G}$ needle. Plasma was immediately separated from cells by centrifugation $\left(4^{\circ} \mathrm{C}, 15 \mathrm{~min}\right.$ at $3000 \mathrm{rpm}$ ) and the extracts were stored at $-18{ }^{\circ} \mathrm{C}$ until assayed. After blood sampling, olfactory bulbs, were removed bilaterally and weighed.

\section{Histology studies}

Olfactory bulbs were removed, frozen rapidly in isopentane at $-70^{\circ} \mathrm{C}$, and stored at this temperature until sectioning. Serial coronal sections $(30 \mu \mathrm{m})$ were collected on a cryostat and thaw mounted onto gelatin-subbed slides. Sections were dried on a hot plate for 1 $\mathrm{h}$, incubated in $10 \%$ formalin for at least $48 \mathrm{~h}$, and stained with cresyl violet. Slides were then dehydrated, cleared, and coverslipped using DPX mounting medium (Aldrich, Milwaukee,WI). Volumes of the external plexiform (CPE), internal plexiform (CGI), and granule cell (CGr) layers (Figure 2) in both right and left olfactory bulbs were measured by projecting images at 403 onto a microcomputercontrolled digitizing tablet and measuring the area of each lamina in every 10th section.

Each lamina was measured twice to determine the mean area. The volume of each layer in the right (experimental) and left (control) olfactory bulbs was then calculated as described previously [19].

\section{Hormone assays}

Corticosterone were measured without an extraction procedure, using a commercially available EIA kit and performed according to the manufacturer's guidelines (Assay Designs Inc., USA). The concentration of corticosterone in plasma samples was calculated from a standard curve and expressed as $\mathrm{ng} / \mathrm{ml}$. The intra- and interassay coefficients of variation were under 8.4 and $13.1 \%$.

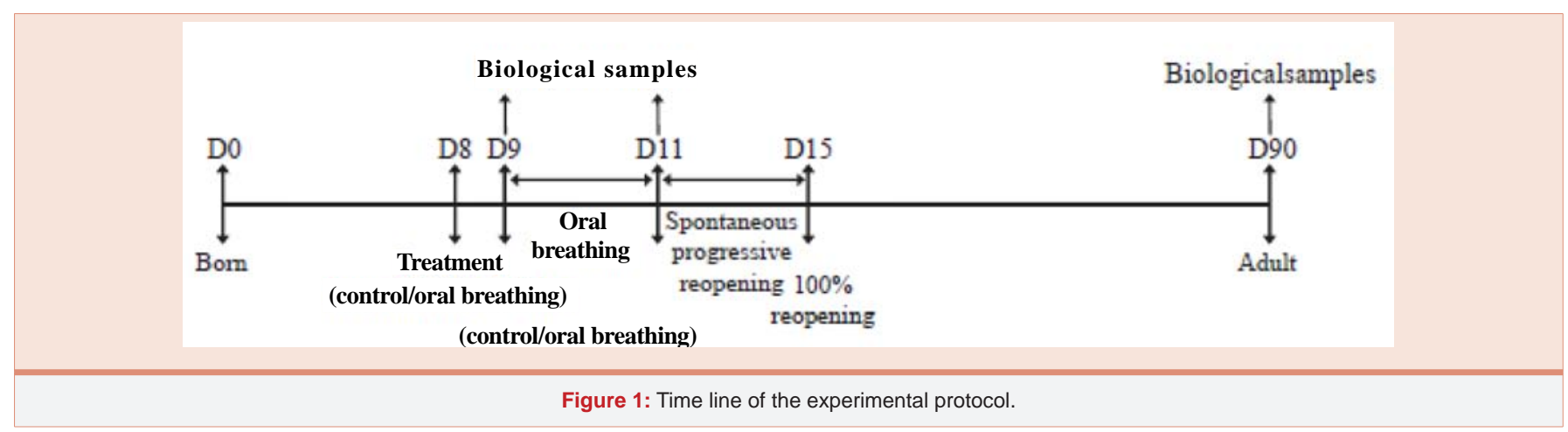




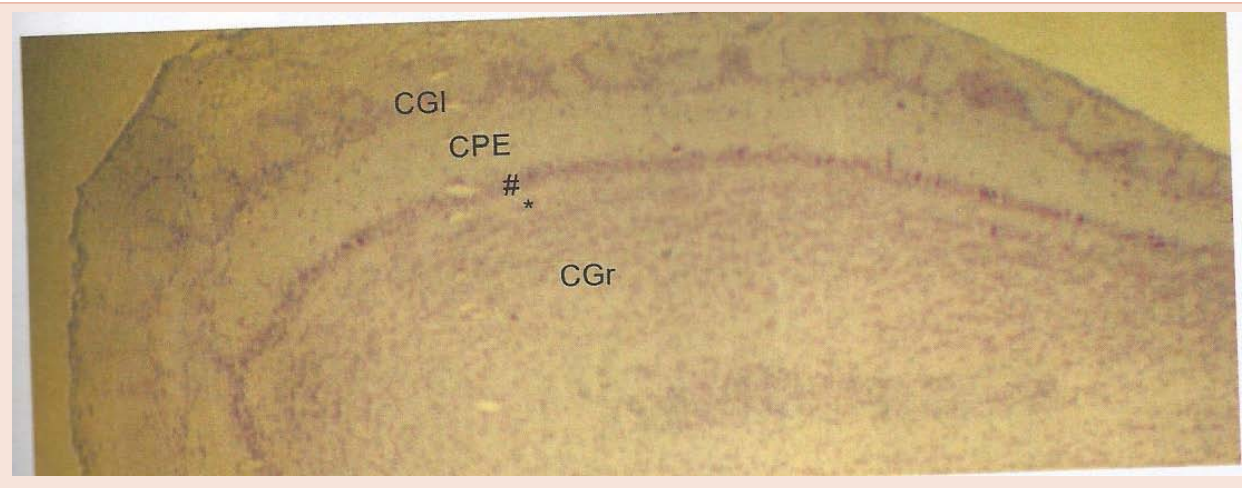

Figure 2: Histology of olfactory bulb (CGI: internal; CPE: external plexiform; CGr granule cell).

Thyroxine (T4) and triiodothyronine (T3) were assayed using commercial RIA kits and performed according to the manufacturer's guidelines (Immunotech SA, Marseille, France). The concentrations of $\mathrm{T} 4$ and $\mathrm{T} 3$ in plasma samples were calculated from standard curves and expressed as $\mathrm{pg} / \mathrm{ml}$. The intra- and inter-assay coefficients of variation were respectively under 6.7 and $6.5 \%$ for T4 and under 6.4 and $5.5 \%$ for $\mathrm{T} 3$.

\section{Statistical analysis}

The results were expressed as group means \pm SEM. Student's t-test was used to establish the comparison between control and oral breathing animals since all data were normally distributed. Body weight group differences were determined using a two-way ANOVA (factor treatment $\times$ factor age). Specific mean comparisons were then made using t-test with the Bonferroni correction. Differences were considered significant at $\mathrm{P}<0.05$.

\section{Results}

\section{Morphometric characteristics}

Before treatment, at 8 days of age, the body weights of control and oral breathing pups were not significantly different. In male group there are $17.78 \pm 0.52 \mathrm{~g}$ and $17.95 \pm 0.28 \mathrm{~g}$, respectively $(\mathrm{p}=0.14)$. The body weights in female was $16.58 \pm 0.42 \mathrm{~g}$ and $16.32 \pm 0.38$ ( $\mathrm{p}=$ $0.48)$ respectively. Table 1 shows no differences in body weights were observed at 90 days in male $(\mathrm{p}=0.28)$ and female group $(\mathrm{p}=0.39)$. Relative olfactory bulb weights are presented in Table 1.

A significant reduction in olfactory bulb specific weight was found for in the nasal obstruction group compared to control animals $(\mathrm{p}<0.0001)$. The reduction was $41 \%$ in nasal obstruction males and $34 \%$ in female compared to control animals.

\section{Histological study}

To check whether nasal obstruction had affected the development of olfactory bulbs histology, the volumes of the external plexiform (CPE), internal plexiform (CGI), and granule cell (CGr) was measured (Table 2).

Results showed that nasal obstruction affect the development of olfactory bulb structure. In female group we observe the decrease volume of CGI (34\%), CPE (37\%) and CGr (47\%). These changes are more important in male experiment group. In male, we observe the decrease volume of CGI (49\%), CPE (55\%) and CGr (70\%)

\section{Hormone assays}

As shown in table 3, plasma corticosterone levels were significantly different between control and experimental female groups $(\mathrm{p}<0.001)$. We observe an increase of plasma corticosterone level (302. 76\%).

No difference was observed in thyroid hormones in female group $(\mathrm{p}>0.05)$.

In male group Table 3 shown that decrease $(\mathrm{p}<0.0001)$ in plasma Thyroids hormones levels was observed (T4: 12\%; T3: 27\%). No difference was observed in corticosterone between control and male experimental group $(\mathrm{P}>0.05)$

\section{Discussion and Conclusion}

Our data show atrophy of the olfactory bulbs. It is well established that induction of an obstruction nasal causes atrophy of the components of the olfactory system. This atrophy has been demonstrated not only in the olfactory mucosa, but also for the olfactory bulb $[20,21]$. Indeed, in the absence sensory stimulation, there is a decrease in the number of cells within the olfactory mucosa, lack of afferent from the mucosa leads to turn down the number of cells in the olfactory bulb. Two assumptions not exclusive can be advanced to explain these changes: a decrease in neo-neurogenis and / or an increase in apoptosis [22,23].

Our results showed that early temporary $(3 \mathrm{~d})$ nasal obstruction

Table 1: Effects of temporary nasal obstruction on body weight $(\mathrm{g})$ and olfactory bulbs specific weights $(\mathrm{mg} / \mathrm{g})$ at 90 days in controls and animals exposed to nasal obstruction.

\begin{tabular}{|l|c|c|}
\hline Females & Body weight (g) & Olfactory bulb (mg/g) \\
\hline Control & $264,44 \pm 4,1$ & $0,22 \pm 0,01$ \\
\hline Oral breathing & $250,6 \pm 8,6$ & $0,13 \pm 0,01^{*}$ \\
\hline Males & & \\
\hline Control & $394,18 \pm 8,65$ & $0,3 \pm 0,01$ \\
\hline Oral breathing & $408,47 \pm 9,61$ & $0,2 \pm 0,01^{*}$ \\
\hline $\begin{array}{l}\text { Values are means } \pm \text { SEM }(\mathrm{n}=7 / \text { group/age }) . \\
\text { * significantly different from }\end{array}$ & \\
\hline
\end{tabular}

*significantly different from control group at 90 days at $\mathrm{P}<0.05$. 
Table 2: Effects of temporary nasal obstruction on olfactory bulbs structure at 90 days in controls and animals exposed to nasal obstruction.

\begin{tabular}{|c|c|c|c|}
\hline Females & CGI (mm) & CPE (mm) & $0,38 \pm 0,06$ \\
\hline Ctrl & $0,32 \pm 0,06$ & $0,83 \pm 0,08$ \\
\hline NO & $0,21 \pm 0,03^{*}$ & $0,24 \pm 0,04^{*}$ \\
\hline Males & & $0,44 \pm 0,07^{*}$ \\
\hline Ctrl & $0,27 \pm 0,08$ & $0,56 \pm 0,07$ \\
\hline NO & $0,14 \pm 0,02^{*}$ & $0,25 \pm 0,02^{*}$ \\
\hline
\end{tabular}

Values are means \pm SEM $(n=7 /$ group/age $)$.

*significantly different from control group at 90 days at $\mathrm{P}<0.05$.

Table 3: Effects of temporary nasal obstruction on physological hormones at 90 days in controls and animals exposed to nasal obstruction.

\begin{tabular}{|c|c|c|c|}
\hline Females & Corticosterone $(\mathbf{n g} / \mathbf{m l})$ & Triiodothyronine (pg/ml) \\
\hline Ctrl & $14,13 \pm 3,7$ & $5,2 \pm 0,4$ \\
\hline NO & $42,78 \pm 6,01^{*}$ & $4,3 \pm 0,6$ \\
\hline Males & & $13,3 \pm 0,01$ \\
\hline Ctrl & $22,53 \pm 6,10$ & $5,8 \pm 0,1$ \\
\hline NO & $27,77 \pm 3,44$ & $3,01 \pm 0,8^{*}$ \\
\hline $\begin{array}{l}\text { Values are means } \pm \text { SEM }(n=7 / \text { group/age }) . \\
\text { *significantly different from control group at } 90 \text { days at } P<0.05 .\end{array}$ \\
\hline
\end{tabular}

associated with forced oral breathing causes changes in olfactory bulb structure. Nasal obstruction was associated with a decrease of the volumes of the external plexiform (CPE), internal plexiform (CGI), and granule cell (CGr) in both sexes. Similar results had already been found by Meisami [1], who showed atrophy of the olfactory bulbs due to nasal obstruction. Several hypotheses had been issued: the first clear -cut demonstration of a growth inhibitory effect in a central sensory structure as a consequence of the mere lack of sensory input to that structure during critical period's brain development. To be sure, true and complete differentiation with consequent axonic and synaptic degeneration has frequently been shown to result in reduced growth [24-26]. A number of causes may underlie the reduced growth in experimental group: reduction in rate magnitude of over -all protein synthesis related to growth; reduction in cell growth and differentiation, particularly with respect to dendritic and synaptic proliferation; reduction in glial and / or neuronal proliferation; reduction in lipid synthesis and myelin formation; reduction in electrical and other neurophysiological activities of the nasal obstruction as a consequence of decrease receptor and afferent stimulation; reduction in blood supply with a consequent state of under nutrition and lowered metabolism.

The decrease in the volume of histological layers of the olfactory bulbs could still involve other factors such as hormonal changes. Nasal obstruction was long associated with hypothyroidism in males and an excess of glucocorticoids in females. In fact, glucocorticoid and thyroid hormones receptor are present on cells of the olfactory bulb from the early stages of development $[27,28]$. Excess glucocorticoids and hypothyroidism have deleterious effects on synaptogenesis [29], and neuronal proliferation in the tendering components of olfactory system [30,31]. In the developing rodent brain hypothyroidism, induce various morphological abnormalities such abnormalities including: a) delayed proliferation and migration of granule cell layer (EGL) to the internal granule cell layer (IGL); b) decreased arborisation of Purkinje cell dendrites; c) decrease synaptogenis between parallel fibers and Purkinje cell dendrite.

In conclusion, the present study has shown that the structure of olfactory and the levels of plasma hormones can be altered by temporary nasal obstruction. For the first time we have demonstrated that olfactory bulb atrophy induces by the nasal obstruction can be explained by a change in the hormonal status observed in the experimental groups. This could indicate that our model of temporary nasal obstruction could be an appropriate model for looking at potential changes in hormones and other physiological parameters of rhinitis or other temporary obstructive nasal breathing pathology.

\section{References}

1. Armengot M, Hernández R, Miguel P, Navarro R, Basterra J (2008) Effect of total nasal obstruction on nocturnal oxygen saturation. Am J Rhinol 22: 325-328.

2. Craig TJ, Ferguson BJ, Krouse JH (2008) Sleep impairment in allergic rhinitis, rhinosinusitis, and nasal polyposis. Am J Otolaryngol 29: 209-217.

3. Rombaux P, Liistro G, Hamoir M, Bertrand B, Aubert G, et al. (2005) Nasal obstruction and its impact on sleep-related breathing disorders. Rhinology 43 : 242-250.

4. Udaka T, Suzuki H, Kitamura T, Shiomori T, Hiraki N, (2006) Relationships among nasal obstruction, daytime sleepiness, and quality of life. Laryngoscope 116: $2129-2132$

5. McGuire M, MacDermott M, Bradford A (2002) Effects of chronic episodic hypoxia on rat upper airway muscle contractile properties and fiber-type distribution. Chest 122: 1012-1017.

6. Balbani AP, Weber SA, Montovani JC (2007) Update in obstructive sleep apnea syndrome in children. Braz J Otorhinolaryngol 71: 74-80.

7. Dempsey JA, Veasey SC, Morgan BJ, O'Donnell CP (2010) Pathophysiology of sleep apnea. Physiol Rev 90: 47-112. 
8. Jefferson $Y(2010)$ Mouth breathing: adverse effects on facial growth, health, academics, and behavior. Gen Dent 58: 18-25.

9. Meisami E (1976) Effects of olfactory deprivation on post natal growth of the rat olfactory bulb utilizing a new method for production of neonatal unilateral anosmia. Brain Res 107: 437-444.

10. Schlenker WL, Jennings BD, Jeiroudi MT, Caruso JM (2000) The effects of chronic absence of active nasal respiration on the growth of the skull: a pilo study. Am J Orthod Dentofacial 117: 706-713.

11. Betlejewski S (1998) Physiology and surgery of the nose. Otolaryngol Pol 52 159-162.

12. Keck T, Leiacker R, Meixner D, Kühnemann S, Rettinger G (2001) Warming inhaled air in the nose. HNO 49: 36-40.

13. deAlmeida VL, Alvaro RA, Haider Z, Rehan V, Nowaczyk B, et al. (1994) The effect of nasal occlusion on the initiation of oral breathing in preterm infants. Pediatr Pulmonol 18: 374-378.

14. Subtelny JD (1980) Oral respiration: facial maldevelopment and corrective dentofacial orthopedics. Angle Orthod 50: 147-164.

15. Laws SC, Stocker TE, Ferrell JM, Hotchkiss MG, Cooper RL (2007) Effects of altered food intake during pubertal development in male and female Wistar rats. Toxicol Sci 100: 194-202.

16. Gomez F, Abdeljalil L, De Kloet ER, Armario A (1996) Hypothalamic-pituitaryadrenal response to chronic stress in five inbred rat strains: differentia responses are mainly located at the adrenocortical level. Neuroendocrinology 63: $327-337$.

17. Waguespack AM, Reems MR, Butman ML, Cherry JA, Coppola DM (2005) Naris occlusion alters olfactory marker protein immunoreactivity in olfactory epithelium. Brain Res 1044: 1-7.

18. Gelhaye M, Martrette JM, Legrand-Frossi C, Trabalon M (2006) Myosin heavy chain expression and muscles adaptation to chronic oral breathing in rat. Respir Physiol Neurobiol 154: 443-452.

19. Loranca A, Salas M (2001) Social play development in pre-weaning olfactory deprived or stimulated rats. Brain Res 7: 150-159.
20. Najbauer J, Leon M (1995) Olfactory experience modulated apoptosis in the developing olfactory bulb. Brain Res 674: 245-251

21. Brunjes $P$, Shurling DC (2003) Cell death in the nasal septum of normal and naris-occluded rats. Brain Res Dev Brain Res 146: 25-28.

22. Farbman A, Brunjes PC, Rentfro L, Michas J, Ritz S (1998) The effect of unilateral naris occlusion on cell dynamics in the developing rat olfactory epithelium. J Neurosci 8: 3290-3295

23. Bauer S, Rasika S, Han J, Mauduit C, Raccurt M, et al. (2003) Leukemia inhibitory factor is a key signal for injury-induced neurogenesis in the adult mouse olfactory epithelium. J Neurosci 23: 1792-1803.

24. Wu HH, Ivkovic S, Murray RC, Jaramillo S, Lyons KM, et al. (2003) Autoregulation of neurogenesis by GDF11. Neuron 37: 197-207.

25. Klosovsky BN, Kosmarskaya EN (1963) Exitatory and inhibitory state of the brain. National Science Foundation, Washington D.C.

26. Powell TP (1967) Transneural cell degeneration in the olfactory bulb shown by Golgi method. Nature 215: 425-426.

27. Risen AH (1975) The developmental neuropsychology of sensory deprivation, Academic press, New York.

28. Morimoto M, Morita N, Ozawa H, Yokoyama K, Kawata M (1996) Distribution of glucocorticoid receptor immunoreactivity and mRNA in the rat brain: an immunohistochemical and in situ hybridization study. Neurosci Res 26: 235269.

29. Galeeva A, Treuter E, Tuohimaa P, Pelto-Huikko M (2002) Comparative distribution of the mammalian mediator subunit thyroid hormone receptorassociated protein (TRAP220) mRNA in developing and adult rodent brain. Eur J Neurosci 16: 671-683.

30. Koibuchi N, Iwasaki T (2006) Regulation of brain development by thyroid hormone and its modulation by environmental chemicals. Endocr J 53: 295303.

31. Van den Hove DL, Steinbusch HW, Bruschettini M, Gazzolo D, Frulio R, et al. (2006) Prenatal stress and neonatal rat brain development. Neurosciences 137: 145-155.

Copyright: (c) 2015 Padzys GS, et al. This is an open-access article distributed under the terms of the Creative Commons Attribution License, which permits unrestricted use, distribution, and reproduction in any medium, provided the original author and source are credited. 